\title{
The Histopathological Characteristics Caused by Trionyx sinensis Hemorrhagic Syndrome Virus (TSHSV) and Comparative Proteomic Analysis of Liver Tissue in TSHSV-Infected Chinese Soft-Shelled Turtles (Pelodiscus sinensis)
}

\author{
Li Liu Zheng Cao Feng Lin Xueping Ye Shujuan Lu Sunjian Lyv
}

Agriculture Ministry Key Laboratory of Healthy Freshwater Aquaculture, Key Laboratory of Fish, Health, and Nutrition of Zhejiang Province, Zhejiang Institute of Freshwater Fisheries, Huzhou, China

\section{Keywords}

Trionyx sinensis hemorrhagic syndrome virus .

Histopathological features · iTRAQ-based proteomic

analysis · Molecular pathogenesis

\begin{abstract}
Trionyx sinensis hemorrhagic syndrome virus (TSHSV) is a pathogen that causes severe hemorrhagic syndrome and irreversible damage to different infected tissues of Pelodiscus sinensis, ending in the death of affected organisms. In the present study, the histopathological characteristics of TSHSV-infected $P$. sinensis were analyzed and compared by $\mathrm{HE}$ staining. Relative and absolute quantification (iTRAQ)based proteomic analysis was employed to explore the molecular pathology of liver injury. Anatomical features indicated that TSHSV caused obvious congestion in the liver, kidney, intestine, and other tissues of $P$. sinensis. The typical clinical symptoms included hepatomegaly, fragility, spotty and severe congestion in liver tissue, and also obvious intestinal bleeding. The histopathological studies corroborated such lesions in the liver and kidney, etc. iTRAQ-based proteomic analysis revealed that there were 252 differentially expressed proteins in the liver tissue between healthy and
\end{abstract}

\section{KARGER}

(C) 2017 S. Karger AG, Basel

E-Mail karger@karger.com

www.karger.com/int infected $P$. sinensis, of which 118 proteins were upregulated and 134 proteins were downregulated. GO enrichment analysis and KEGG pathway analysis initially revealed the molecular mechanism of pathological changes in $P$. sinensis by TSHSV infection. The expression of some differentially expressed proteins was further confirmed by qRT-PCR. These results provided important information for the pathological diagnosis of TSHSV-caused disease, as well as the mechanism underlying TSHSV-caused disease.

(c) 2017 S. Karger AG, Basel

\section{Introduction}

The Chinese soft-shell turtle (Pelodiscus sinensis) is a famous freshwater-farmed species in China because of its unique nutritional value $[1,2]$. However, pathogencaused diseases are an important limiting factor for the healthy and sustainable development of the turtle farming industry [3]. Compared to fish diseases, most of the reports on turtle diseases are focused on clinical diagnosis and treatment studies [4-6], whereas the basic research associated with turtle disease is relatively weak and the pathogens causing turtle disease are still unclear. 
Table 1. Primers used in $\mathrm{qRT}-\mathrm{PCR}$

\begin{tabular}{|c|c|c|c|}
\hline Gene name & Primer name & Primer sequence $\left(5^{\prime}-3^{\prime}\right)$ & Size of amplicon, bp \\
\hline Mx1 & $\begin{array}{l}\text { Mx1-F } \\
\text { Mx1-R }\end{array}$ & $\begin{array}{l}\text { gaagtggaccctgatggaga } \\
\text { agaggccagggttaggttgt }\end{array}$ & 183 \\
\hline RSAD2 & $\begin{array}{l}\text { RSAD2-F } \\
\text { RSAD2-R }\end{array}$ & $\begin{array}{l}\text { caggaggagagccatttctg } \\
\text { cgatgtggcttttgtttcct }\end{array}$ & 237 \\
\hline OAS & $\begin{array}{l}\text { OAS-F } \\
\text { OAS-R }\end{array}$ & $\begin{array}{l}\text { ttcctgaaggagacgtgctt } \\
\text { tcagtttctgctcgatggtg }\end{array}$ & 190 \\
\hline C-lectin & $\begin{array}{l}\text { Clectin-F } \\
\text { Clectin-R }\end{array}$ & $\begin{array}{l}\text { gcccttgtgattgtcaggtt } \\
\text { tatgaaacgaggggaactgc }\end{array}$ & 195 \\
\hline PLA2G4 & $\begin{array}{l}\text { PLA2G4-F } \\
\text { PLA2G4-R }\end{array}$ & $\begin{array}{l}\text { acagtttggaccaggtttcg } \\
\text { Tggacgttgccagtttgata }\end{array}$ & 215 \\
\hline ALC & $\begin{array}{l}\text { ALC-F } \\
\text { ALC-R }\end{array}$ & $\begin{array}{l}\text { gaaagatggctgctcacctc } \\
\text { caatcgtgtcctggaatcct }\end{array}$ & 244 \\
\hline RPL34e & $\begin{array}{l}\text { RPL34e-F } \\
\text { RPL34e-R }\end{array}$ & $\begin{array}{l}\text { taggcaaggcaccaaagtct } \\
\text { tctgtgcttgtgccttcaac }\end{array}$ & 225 \\
\hline$\beta$-Actin & $\begin{array}{l}\beta \text {-Actin-F } \\
\beta \text {-Actin-R }\end{array}$ & $\begin{array}{l}\text { tcaccaccacagctgaaagg } \\
\text { ccatacccaggaaggatggc }\end{array}$ & 210 \\
\hline
\end{tabular}

The major pathogens causing turtle diseases include bacteria and viruses. In farm conditions, monitoring of breeding density and improving water quality are recurrent practices to control pathogens such as bacterial infections. However, viral diseases, especially the outbreak of high pathogenic viruses, often lead to high losses in turtle farms, thus representing a threat to the soft-shell turtle farming industry. Currently, there is a relative lack of research available on viruses infecting turtles, and our understanding of these viral pathogens is very limited, with most existing knowledge based on observations from the electron microscope [7-9]. The viruses infecting $P$. sinensis that have been reported include irido-like virus [9], herpes-like virus [5], reo-like virus, rhabdo-like virus [10], Trionyx sinensis spherovirus [7], and T. sinensis virus (TSV) [11]. In recent years, there have been relatively more studies conducted on irido-like virus [1215], which could be the causative agent of "red neck disease," but there is still some controversy about its pathogenicity.

T. sinensis hemorrhagic syndrome virus (TSHSV) was isolated from a fatal case with a sign of hyperemic laryngeal mucosa. It was identified as a virus in infection experiments and part of the nucleotide sequence of TSHSV was also obtained [16]. The present study analyzed the histopathological features caused by TSHSV infection and also investigated proteomic profile chang- es of liver tissue from infected and uninfected turtles using ITAQ technology, and initially analyzed the molecular pathogenesis and pathological characteristics of TSHSV.

\section{Materials and Methods}

\section{Infection Assay}

The preparations of crude virus used for infection challenge were as follows. The tissues (lung, heart, spleen, and kidney) from TSHSV-infected turtles with clinical symptoms were homogenized and centrifuged, the supernatants were filtered through a $0.22-\mu \mathrm{m}$ membrane, and the filtrate was used as crude virus. The virus load was further estimated by real-time PCR and virus preparations were stored at $-80^{\circ} \mathrm{C}$. To perform viral infection, viral preparations corresponding to $2 \times 10^{7}$ copies were injected intramuscularly into the hind limbs of 10 turtles with a weight of 300$500 \mathrm{~g}$, respectively. Another group of 10 turtles injected with PBS was used as the control group. The injected turtles of different groups were conventionally bred at $25-28^{\circ} \mathrm{C}$ in 2 separated containers to avoid cross-infection, and continuously observed during the breeding. All animal experiments were conducted according to the Institutional Animal Care Committee guidelines for the care and use of animals in research.

\section{Collection of Tissues for Experiments}

The tissues, including the liver, spleen, lung, kidney, intestines, and heart, were individually sampled from the turtles in infection assays when signs and symptoms of hypoxia and weak neck developed 4 days after infection. Each tissue was divided into 3 parts, 

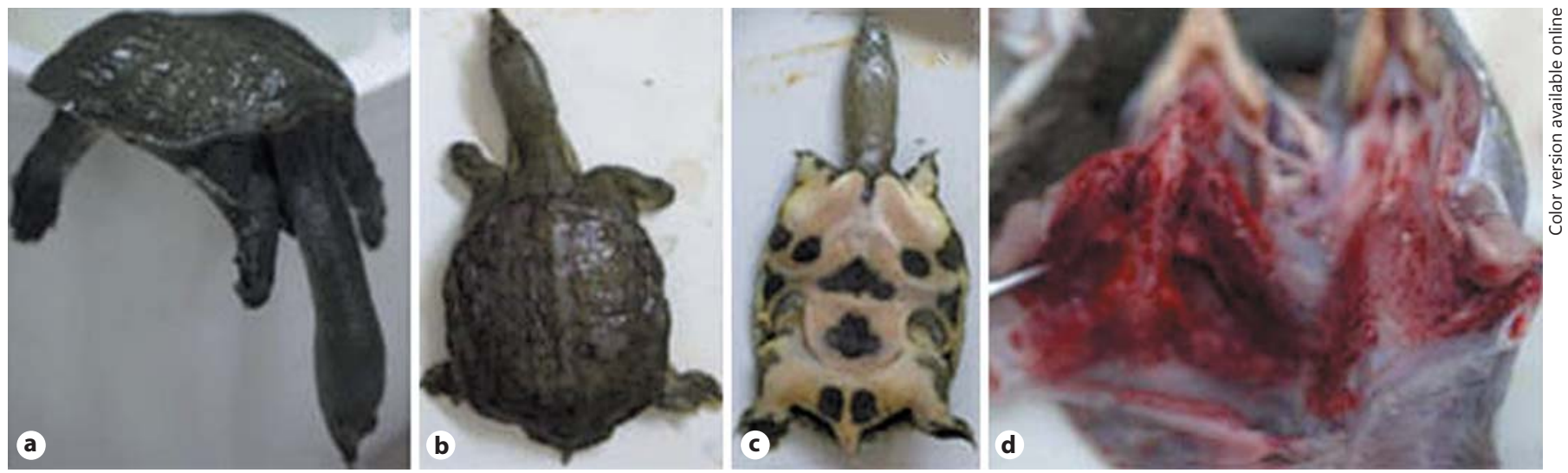

Fig. 1. Clinical manifestations of the infected turtles, including weak neck (a), the plastron and front of shell being normal $(\mathbf{b}, \mathbf{c})$, and hyperemic laryngeal mucosa $(\mathbf{d})$.

which were used for subsequent experiments, such as histopathological analysis and proteomic analysis. All animals were sacrificed according to the Institutional Animal Care Committee guidelines for the care and use of animals in research.

Tissue Damage in Infected Turtles

Tissue were cut from the same locations in the turtles and the lesions were observed and recorded.

\section{Histopathological Analysis}

The organs (liver, spleen, lung, kidney, intestines, etc.) were immediately fixed with $4 \%$ paraformaldehyde and paraffin embedded. The samples were sliced at $6 \mu \mathrm{m}$ and HE stained. The histopathological features from infected and uninfected turtle tissues were observed and compared.

\section{The Comparative Proteomic Analysis of Liver Tissue from \\ Virus-Infected and Uninfected Turtles}

iTRAQ-based proteomic analysis was used to analyze the differentially expressed proteins of infected and uninfected turtles. The liver samples were collected from the same turtle tissues that were used for histopathological analysis, in order to guarantee the consistency in proteomic and histopathological analysis. For iTRAQ assay, the mixed samples of each group including 3 biological replicates were used. The liver samples were flash frozen in liquid nitrogen. After grinding to powder, the samples were dissolved into lysis buffer ( $9 \mathrm{M}$ urea, 4\% CHAPS, $1 \%$ DTT, $1 \%$ IPG buffer; GE Healthcare) and incubated for $1 \mathrm{~h}$ at $30^{\circ} \mathrm{C}$. The samples were then centrifuged for $15 \mathrm{~min}$ at $15,000 \mathrm{~g}$. The proteins in supernatant were measured by the Bradford method. In total, $100 \mathrm{mg}$ of each sample was dissolved in the buffer (AB Sciex, Foster City, CA, USA) prior to alkylation and tryptic digestion, and labeled by iTRAQ reagents 8-plex kit (AB Sciex) according to manufacturer's instructions. The labeled samples were pooled and purified by HPLC, and isolated by LC-MS. The isolated components were analyzed by Triple TOF 5600 mass spectrometer (AB SCIEX). The iTRAQ data were analyzed with the $P$. sinensis database using Protein Pilot Software v4.0. The differentially expressed proteins were determined based on the ratios of labeled proteins and $p$ values provided by Protein Pilot. Proteins with a fold change of 1.3 and a $p$ value $<0.05$ were considered to be significantly differentially expressed.

For GO and KEGG pathway enrichment analysis, the homology search was first performed for all query protein matches with blastp against the $P$. sinensis protein database. The GO analysis was performed with different mapping steps to the functional information stored in the Gene Ontology database using the DAVID toolkit. Public resources such as NCBI, PIR, and GO were used to create links with protein IDs and corresponding gene ontology information. KEGG pathway enrichment analysis was performed using annotated proteins in the query dataset against the KEGG database.

\section{Verification of Differentially Expressed Proteins}

To validate the results obtained from the proteomic analysis, some differentially expressed proteins related to antiviral infectious immunity and some significantly altered proteins associated with metabolism were selected and further confirmed by real-time PCR. Five turtles from each group were selected and their livers were removed and flash frozen in liquid nitrogen, and then ground to powder. The total RNA was extracted with the RNAiso plus reagent (Takara, Japan) following the manufacturer's instructions. The SYBR green qRT-PCR assay was used for the quantification of identical samples. The amplification profile involved denaturation at $94^{\circ} \mathrm{C}$ for $5 \mathrm{~min}$, followed by 40 cycles of $94^{\circ} \mathrm{C}$ for $30 \mathrm{~s}, 60^{\circ} \mathrm{C}$ for $15 \mathrm{~s}$, and $70^{\circ} \mathrm{C}$ for $30 \mathrm{~s}$, in which fluorescence was acquired. At the end of the PCR cycles, melting curve analyses were performed. Each sample was run in triplicate for analysis. All of the primers used in qRT-PCR are shown in Table 1.

The data were presented as relative expression levels compared with $\beta$-actin, and all experimental data were subjected to 1-way analysis of variance followed by Duncan multiple tests to determine differences in the mean values among the controls. Significant differences between the infected and uninfected groups for verified proteins are indicated as $* p<0.05$ and $* * p<0.01$. The error bars in the graphs represent standard deviations. 

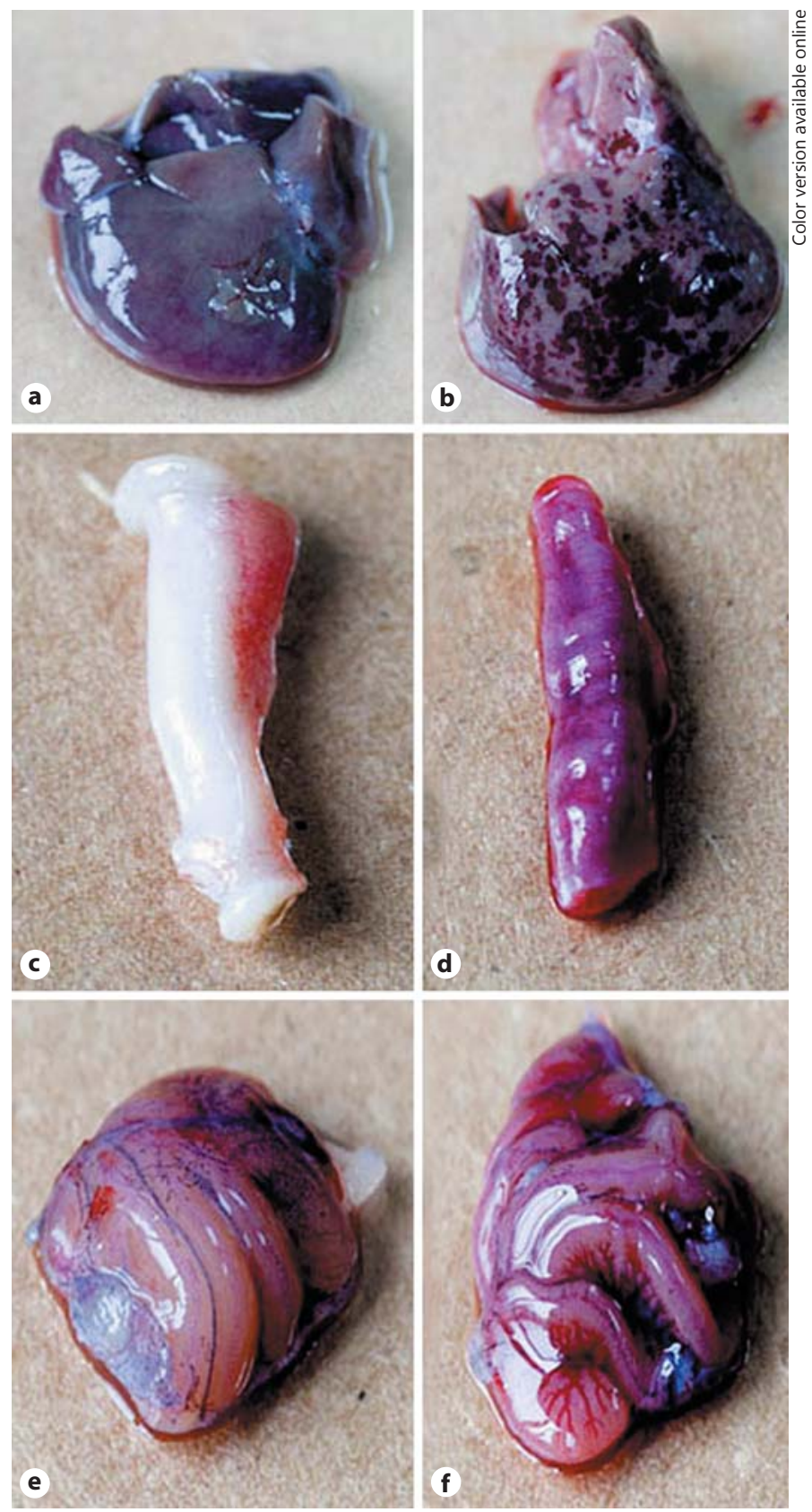

Fig. 2. Anatomical and histopathological characteristics of the infected turtles. a The liver from a healthy turtle. $\mathbf{b}$ The liver from an infected turtle showing hepatomegaly and severe congestion. $\mathbf{c}$ The intestine from a healthy turtle. d The intestine from an infected turtle showing severe congestion. e The kidney from a healthy turtle. $\mathbf{f}$ The kidney from an infected turtle showing swelling and congestion.

\section{Results}

\section{Clinical Manifestations and Anatomical Features of} Infected Turtles

It was observed that the typical symptoms in the turtles appeared 4 days after virus infection and the main manifestation was hypoxia and weak neck, whereas the plastrons and front of the shells appeared normal and there were no swelling symptoms in the body (Fig. 1a-c). After dissection, hyperemic laryngeal mucosa was observed (Fig. 1d). Typical clinical manifestations included hepatomegaly, fragility, spotty and severe congestion in liver tissue (Fig. 2b), and obvious intestinal bleeding (Fig. 2d) without perforation. Some sick turtles had pale intestines after massive blood loss, but bloodshot on the intestinal walls was still observable. Moreover, congestion and swelling in the kidney of sick turtles were also visible (Fig. 2f). Other tissues, such as the spleen, lung, and gonad, etc., also represented signs of hyperemia of various degrees (data not shown). On the other hand, splenomegaly was not observed.

Histopathological Lesions in Tissues of Infected Turtles

Compared with the control group, massive damage of tissues in turtles with clinical syndrome at 4 days postinfection could be observed by pathological section, as shown in Figure 3. Cells were severely damaged in liver tissue sections. Cells and cell cord structures were obscure and disorderly arranged. Hepatocytes necrosis with nuclear dissolution was also observed. In some areas cells had shrunk and were necrotic, and had lost their arrangement and the basic structure of cellular organization was changed. In intestinal tissue sections, mucosal epithelial cells were necrotic and disintegrated, intestinal villi were broken and the capillaries were congested in lamina propria. A large number of necrotic and disintegrated intestinal epithelial cells were present in the intestinal lumen. The nuclear morphology had changed and the bowel wall was thickened in lung tissue sections, while most capillaries in the alveolar walls and small veins were dilated and congested. Nuclear dissolution, cytoplasmic swelling, and structural changes were observed. In kidney tissue sections, we observed compensatory glomerular hypertrophy and dilated, enlarged tubules. Some glomerular atrophy, changes in renal cyst size, and glomerular disintegration were seen. Granular degeneration and hyaline droplets were observed in epithelial cells. We also observed a lighter color for nuclear staining and increased interstitial fibrous tissue with lymphocytic infiltration. In addition, the tissue lesions in lungs and spleens from in- 
Fig. 3. Histopathological features of different tissues from infected turtles. a Intestinal tissue from a healthy turtle. b Intestinal tissue from an infected turtle. c The liver from a healthy turtle. $\mathbf{d}$ The liver from an infected turtle. e The kidney from a healthy turtle. f The kidney from an infected turtle. Scale bars, $20 \mu \mathrm{m}$.
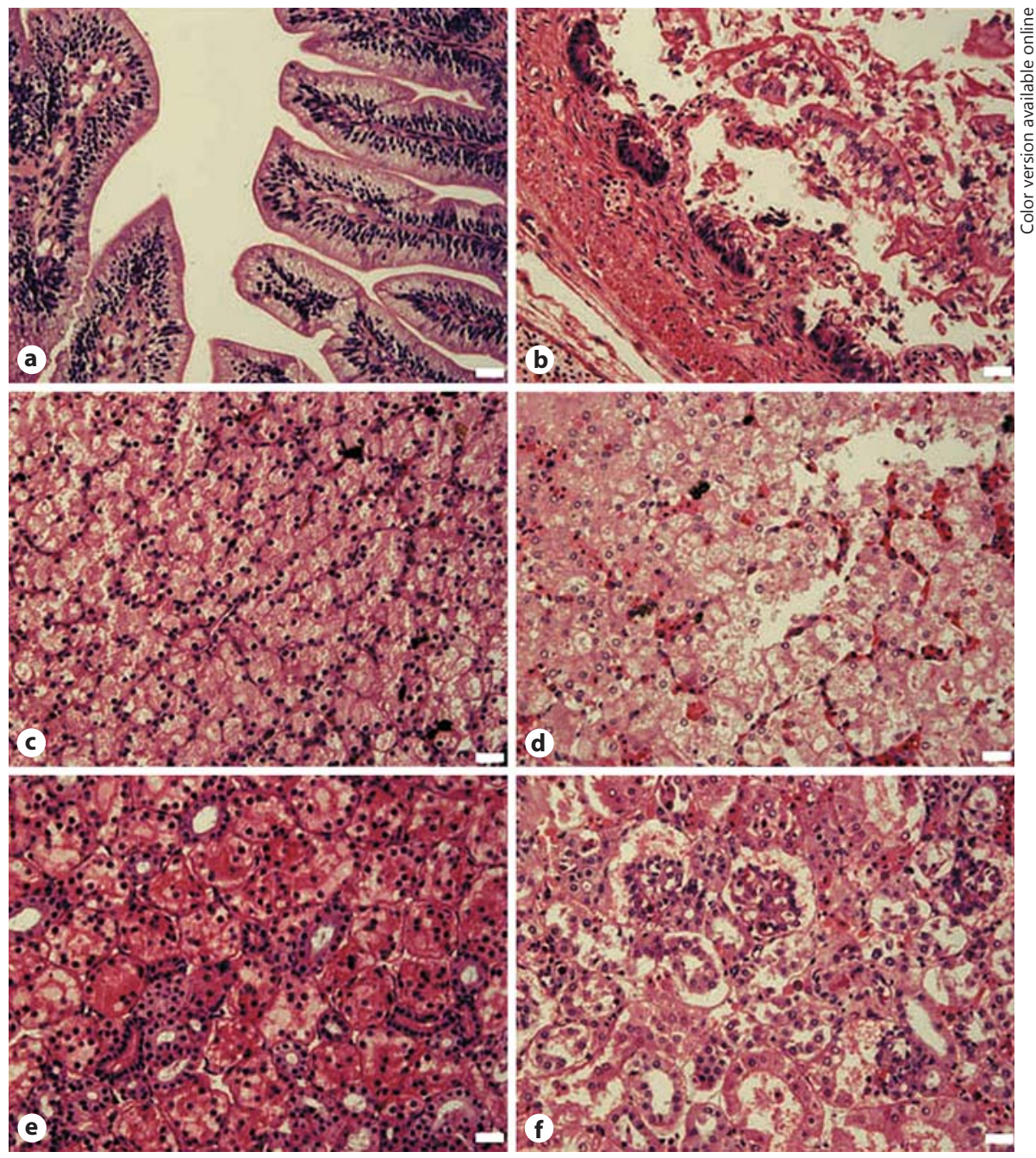

fected turtles were easily observed by comparison with the histopathological features (data not shown).

\section{Comparative Proteomic Analysis}

Using an iTRAQ quantitative proteomics approach, a total of 2,236 proteins were identified, and 252 of them were determined by the response to TSHSV infection (fold change above 1.3 and $p$ value $<0.05$ ). Among them, it was observed that the expression of 118 proteins was upregulated and the expression of 134 proteins was downregulated. The identified differential proteins were evaluated in biological process, BP, cellular component, CC, and molecular function, MF, using functional annotation analysis (http://www.geneontology.org/). BP analysis found that most of the "differential" proteins are involved in the signaling transduction, metabolism, cell physiological process, and external stimuli. MF analysis indicated that these proteins are associated with molecular binding, catalytic activity, structural molecular activity, electron carrier activity, and other functions. CC analysis demonstrated that differential proteins are mainly distributed in cytoplasmic, organelles, macromolecular complexes, and cell membrane (Fig. 4). These results demonstrated that the differentially expressed proteins were mainly involved in catalytic activity, metabolism, molecular binding, and cell physiological processes, indicating that viral infection has a broad impact on physiological activities of host live tissue. KEGG pathway analysis showed that the predominant signaling pathways were ribosome, fatty acid metabolism, and peroxisome proliferator-activated receptor (PPAR) pathways, which initially revealed the molecular mechanism of pathological changes after the infection of $P$. sinensis by TSHSV. From these "differential" proteins, we found multiple upregulated molecules involved in an- 
Fig. 4. a The distribution of differentially expressed proteins in GO terms of level 2. b The distribution of differentially expressed proteins in subcellular locations. extr, extracellular space; plas, cytoplasm; cysk, cytoskeleton; ER_mito, endoplasmic reticulum-mitochondria; nucl, nucleus; cyto_pero, cytochrome-peroxisome; golg, Golgi apparatus; mito, mitochondria; cyto, cytochrome; ER, endoplasmic reticulum; pero, peroxisome; cyto_nucl, cytoplasmnucleus.

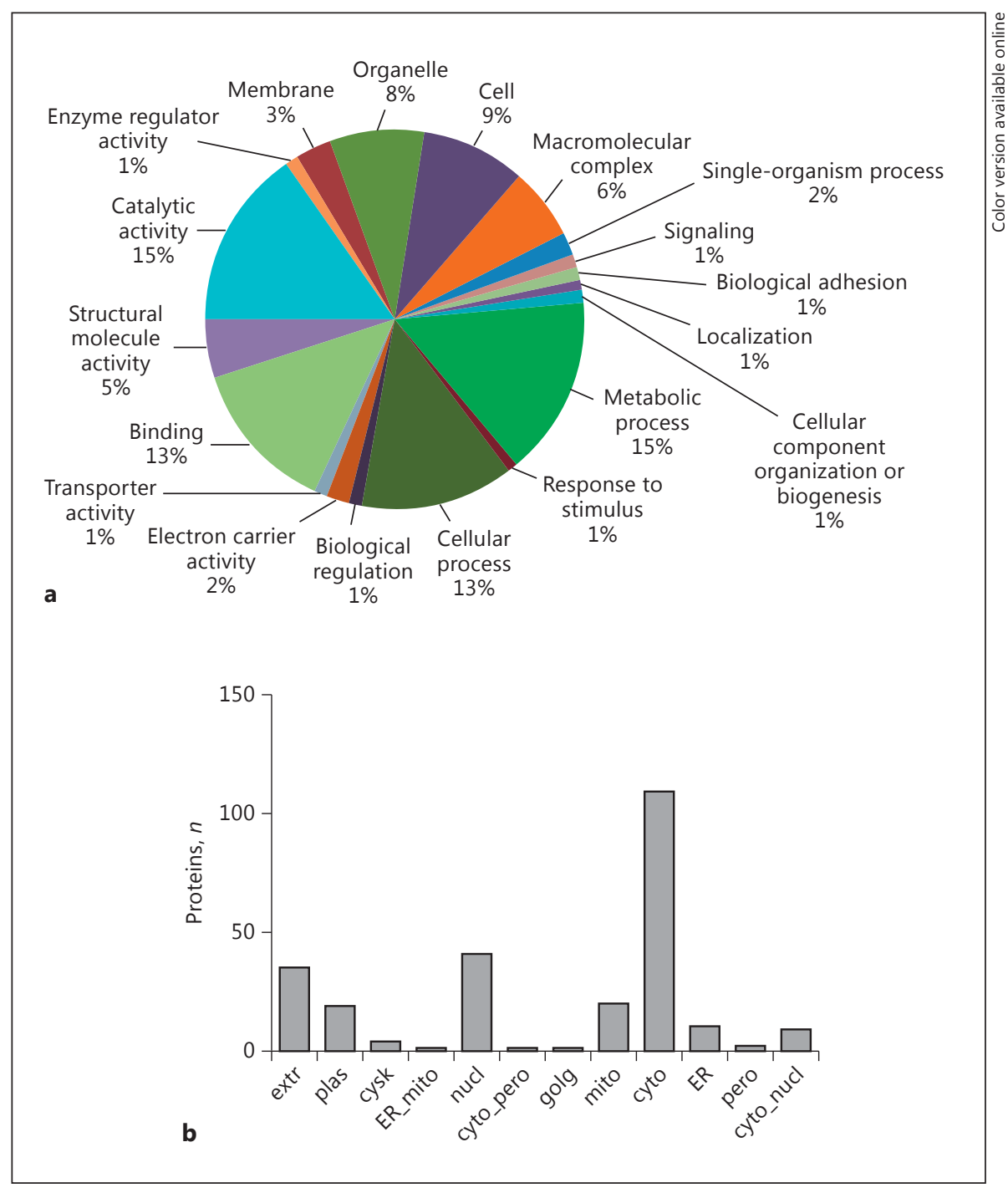

tivirus responses, including 2-5 oligoadenylate synthetases (OAS), radical S-adenosyl methionine domain-containing protein 2 (RSAD2), and interferon-induced GTPbinding protein $\mathrm{Mx} 1$.

\section{Verification of Differentially Expressed Proteins}

According to the bioinformatic analysis of proteomics data, differentially expressed protein genes Mx1, RSAD2, OAS, C-lectin, cytosolic phospholipase A2 (PLA2G4), allantoicase (ALC), and large subunit ribosomal protein L34e (RPL34e) were selected for further verification with real-time RT-PCR. It was shown that infection of $P$. sinensis with TSHSV significantly upregulated the expression level of the anti-infection-related genes $(\mathrm{Mx} 1$, RSAD2, OAS, and C-lectin) and lipid metabolism-related gene PLA2G4, whereas the transcription levels of ALC and RPL34e were significantly downregulated compared with the uninfected group (Fig. 5), which was consistent with the proteomic analysis data.

\section{Discussion}

Pathological features represent the major basis for the diagnosis and treatment of diseases. Recently, outbreaks of a highly fatal disease with the symptom of hyperemic laryngeal mucosa have frequently occurred in the Chinese soft-shelled turtle farming industry. So far, most of the research in this field has focused on the clinical diagnosis and treatment of the disease, and diagnosis has 


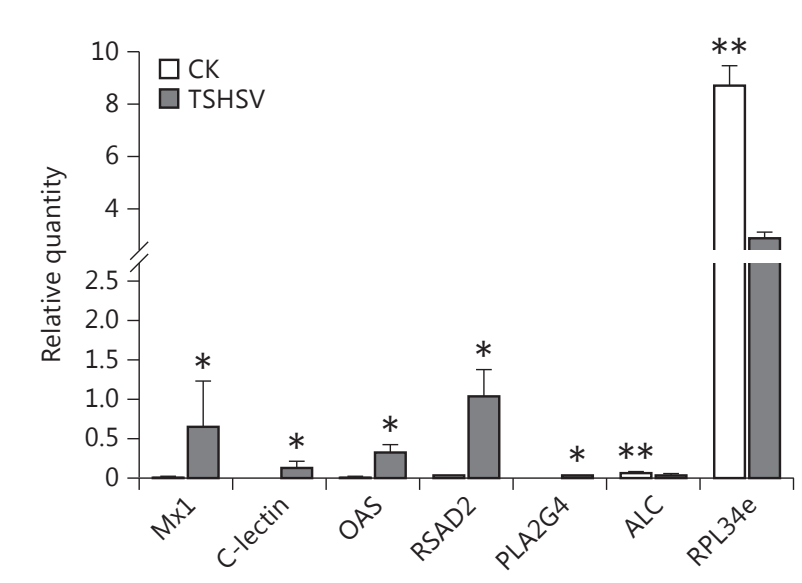

Fig. 5. Selection of differentially expressed proteins in the livers of the infected and uninfected groups. Significant differences between infected and uninfected control groups are indicated: ${ }^{*} p<$ $0.05,{ }^{* *} p<0.01$. Error bars represent standard deviations. CK, uninfected control groups

mainly relied on clinical features, such as the swelling and bleeding of laryngeal mucosa, and high mortality rate. However, similar clinical symptoms were also observed in bacterial pathogen-caused turtle diseases [17], which significantly affected the accuracy of diagnosis. Therefore, a more in-depth pathological analysis is important for the diagnosis of the disease and our understanding of its pathogenesis. Our previous study found that TSHSV was highly pathogenic in $P$. sinensis. In clinical performance, it causes suspected symptoms of Chinese softshelled turtle hyperemic laryngeal mucosa. From an anatomical point of view, the virus causes significant bleeding of different tissues, and most notably in the liver, intestine, and kidney, which is consistent with TSV infection-caused symptoms [18]. TSV was the first reported nonenveloped spherical virus isolated from sick $P$. sinensis with a diameter of $30 \mathrm{~nm}$. This virus and the disease it causes have been studied from multiple aspects, including morphology, histopathology, cell lesions [19], and immunology. There were some differences after the comparison of clinical symptoms and the characteristics of cases between these 2 viruses. Based on the clinical symptoms, most of the plastrons from TSV-infected turtles have large bleeding spots and the animals have a weak neck, whereas there was no obvious exterior damage on the TSHSV-infected turtles. TSV infection causes hepatosplenomegaly and fragility. On the contrary, the spleen

Pathological Features Caused by TSHSV size of TSHSV-infected turtles was relatively normal by naked eye observation for multiple clinical cases. Additionally, the preliminary study by electron microscopy showed that TSHSV was an enveloped virus measuring $60-80 \mathrm{~nm}$ in diameter, and part of the nucleotide sequence of TSHSV showed homology to viruses of the Arteriviridae family [16]. Because there was no subsequent report on the nucleotide sequence of TSV, further comparison of the sequence at a molecular level between these 2 viruses cannot be performed. Yan et al. [20] analyzed different tissues of turtles with symptoms of hyperemic laryngeal mucosa using light microscopy and electron microscopy. Based on the observation from light microscopy, the histopathological features of the livers and kidneys from infected turtles were similar to TSHSV infection; the pathological damage of the spleen was severe, whereas there was less damage in intestinal tissue. It was speculated that the infection was caused by a virus, but there no subsequent studies were conducted on related pathogens.

Based on the observation from previous clinical cases and infection experiments, it was found that the damage from liver tissues of infected turtles was severe and the liver tissues in most cases were spotty and had multiple bleeding spots, with some showing acute hepatic necrosis and cirrhosis. The staining of tissue sections also showed obvious pathological damage. We therefore performed a comparative proteomic analysis of liver tissue from virusinfected and uninfected turtles using iTRAQ technology. It was found that the "differential" proteins were involved in the signaling pathways that were associated with ribosome, lipid metabolism, and PPAR pathways, indicating that TSHSV infection affected the metabolic activity of host live tissues and resulted in broad tissue damage. The liver plays important roles in fatty acid and cholesterol metabolisms. It is not only a major organ for the synthesis of fatty acids and lipid, but also the most productive organ for the synthesis of cholesterol. In recent years, it was also found that PPARs are closely related to energy metabolisms (lipid, glucose), cell differentiation, cell proliferation, cell death, and inflammatory response [21,22].

In addition, the real-time PCR results also showed that the antiviral infection-related genes (Mx1, OAS) were also upregulated during TSHSV infection, suggesting that tissue damage was related to the viral infection. The protein Mx1 has antiviral activity induced by interferon in vertebrates. The infection of pigs with porcine reproductive and respiratory syndrome virus (PRRSV) could induce the expression of Mx1 [23]. IFN- $\alpha$ and Mx1 played an important role in host defense against PRRSV infec-

Intervirology 2017;60:19-27 DOI: $10.1159 / 000479795$ 
tion at early stages, as shown by studies on the expression of IFN- $\alpha$ and Mxl during the acute infection of pigs with PRRSV [24]. The previous study found some similarity between TSHSV and PRRSV [16], and the induced expression of Mx1 was also similar to PRRSV infection.

The OAS protein $\left(2^{\prime}-5^{\prime}\right.$-oligoadenylate synthetase $)$ is an important component of innate immunity in mammals and an interferon-induced antiviral protein [25]. It has been found that OAS is an antiviral biomarker gene in mice, horses, and humans. In the present study, we found that expression of OAS in the liver tissues of infected turtles was upregulated, suggesting that TSHSV infection can induce the expression of antiviral proteins. RSAD is a protein family with more than 600 members involved in multiple physiological and biochemical reactions, such as methylation, isomerization, anaerobic oxidation, and free radicals. Among them, viperin (virus inhibitory protein), also known as RSAD2, is an interferoninduced protein with virus replication inhibitory activity. This protein is associated with the host antiviral response and is one of the major antiviral effectors in host cells, showing antiviral activity to human cytomegalovirus, hepatitis C virus, and HIV-1 [26-28]. It was speculated that viperin might inhibit virus replication by disruption of lipid raft formation and inhibition of virus bud release by binding to the inactivated FPPS [29]. Viperin showed antiviral activity for equine infectious anemia virus [30], sindbis virus [31], and PRRSV [32]. Our early observation from electron microscopy showed that TSHSV is an enveloped virus, and part of its nucleotide sequence has some homology to arteritis virus [16]. It was speculated that the elevated expression of RSAD was related to the antiviral response. The present study also found that TSHSV infection also caused the upregulation of lectin. Lectin is closely related to protein regulation, cell growth, and cell homeostasis. Some lectin proteins act as patternrecognition receptors to recognize the pathogen-associated molecular patterns during the infection, and are involved in the pathogen invasion, dissemination, cell apoptosis, and host cell death [33]. Some studies suggested that lectin can inhibit HIV infection through competition with the virus for binding on the glycoprotein receptor of T lymphocytes, and therefore inhibited the binding of HIV on cells. However, some lectin proteins can inhibit HIV replication by suppression of the HIV reverse transcription or virus integration process [34].

Additionally, the present study found that the expression of the phospholipase gene PLA2G4 was elevated after TSHSV infection, but the increased level of expression was not as high as other infection-related genes. It has been shown that PLA2G4 played an important role in $\mathrm{HCV}$ replication. PLA2G4 has been shown to be involved in the virus-induced membranous web formation by interacting with the NS4B protein and also HCV assembly [35]. Moreover, it was also shown that TSHSV infection caused the downregulation of allantoate enzymes and ribosomal protein RP-L34e, suggesting that TSHSV infection has a broad effect on the host metabolism, which may be closely related to tissue lesions.

The existing clinical cases and infection experiments showed that TSHSV was highly pathogenic, and was a major threat to the breeding industry of Chinese softshell turtles. However, knowledge about TSHSV is very limited. Further study is warranted concerning the biological characteristics, epidemiology, pathogenesis, and pathogenicity of the virus to other reptiles.

\section{Acknowledgements}

This study was funded by Zhejiang Provincial Natural Science Foundation of China (Project No. LY15C190001).

\section{Disclosure Statement}

The authors declare that they have no conflicts of interest.

References

1 Wang DZ, Rong TZ, Jun TY: Biochemical compositions of Chinese soft-shelled turtle (Trionyx sinensis). I. Contents of normal nutrients and composition of muscle fatty acids. Acta Hydrobiol Sin 1997;21:299-305.

2 Huang CH, Lin WY, Chu JH: Dietary lipid level influences fatty acid profiles, tissue composition, and lipid peroxidation of softshelled turtle, Pelodiscus sinensis. Comp Biochem Physiol Mol Integr Physiol 2005;142: 383-388.
3 Li XL, Zhang CL, Fang WH, Lin FC: Whitespot disease of Chinese soft-shelled turtles (Trionyx sinens) caused by Paecilomyces lilacinus. J Zhejiang Univ Sci B 2008;9:578581.

4 Hong ML, Fu LR, Wang RP, Shi HT: The advances in the research of the turtle's disease. Chin J Zool 2003;38:115-119.

$5 \mathrm{Hu}$ SJ: Prevention and treatment of herpes virus infection in soft-shelled turtle by moroxydine hydrochloride. Fish Sci Technol Inf 1995;22:21-22. 
6 Pu R: Turtle mumps and its treatment. Freshw Fish 1996;26:42-43.

7 Chen P, Chi XC, Chen XF, Wu DH, Huang H: Ultrastructure evidence for a spherovirus infecting cultured Trionyx sinensis. J Xiamen Univ 1997;36:626-630.

8 Chen XZ, Huang YR, Yan JH: The pathogenicity and its ultrastructural evidence of Trionyx sinensis virus. Fujian J Anim Husbandry Vet Med 1998;1:6-7.

9 Chen ZX, Zheng JC, Jiang YL: An iridovirus isolated from sick soft shelled turtle with "red neck disease." Chin J Vet Sci 1998;18:135139.

10 He JG, Wen SP, Ye QZ, Qiu DQ, Wang XH, Zhang BJ, Ye PR, Liang RJ, Pan L: Trionyx sinensis virus and histopathological report. Sun Yatsen Univ Forum 1996;suppl 1:58-60.

11 Zhang QY, Li ZQ, Jiang YL, Liang SC, Gui JF: The discovery of virus causing Trionyx sinensis disease. Chin Sci Bull 1996;41:1987-1990.

12 Xiao F, Zhang YQ: Molecular biology of iridoviruses from aquatic animals. Acta Hydrobiol Sin 2004;28:202-206.

13 Zhang M, Lin XM, Jiang YL: Development of a nested PCR detection method for Ranavirus. J Fish Sci China 2011;18:661-666.

14 Zhu CH, Liu H, Liu XD, Yang JX, Zheng ZY, Lin TL: Preparation and epitope analysis of monoclonal antibodies against soft shelled turtle iridovirus (STIV). J Fish China 2009;33: 840-846.

15 Zhu $\mathrm{CH}$, Liu H, Yang JX: Purification and analysis of soft-shell turtle iridovirus. Fujian J Agr Sci 2009b;24:132-136.

16 Liu L, Cao Z, Lin F, Ye XP, Xu Y: Partial sequence of a novel virus isolated from Pelodiscus sinensis hemorrhagic disease. Intervirology 2015;58:197-204.

17 Chen JS, Zhu NY, Kong L, Bei, YJ, Zheng TL, Ding XY, He ZY: First reported fatal Bacillus thuringiensis infections in Chinese softshelled turtles (Trionyx sinensis). Aquaculture 2014;428-429:16-20.
18 Zhang QY, Li ZQ, Gui JF: Cellular pathological studies on virus infection of soft shelled turtles. Chin J Viol 1999;15:50-54.

19 Zhang QY, Li ZQ: Susceptibility of fish cell lines to Trionyx sinesis virus. Chin J Vet Sci 2000;20:15-18.

20 Yan SF, Jiang YH, Ji RX: Study of parotitis histopathology of soft shelled turtle. J Jimei Univ 2006;11:1-7.

21 Janssen AW, Betzel B, Stoopen G, Berends FJ, Janssen IM, Peijnenburg AA, Kersten S: The impact of PPAR $\alpha$ activation on whole genome gene expression in human precision cut liver slices. BMC Genomics 2015;16:760.

22 Laganà AS, Vitale SG, Nigro A, Sofo V, Salmeri FM, Rossetti P, Rapisarda AM, La Vignera S, Condorelli RA, Rizzo G, Buscema M: Pleiotropic actions of peroxisome proliferator-activated receptors (PPARs) in deregulated metabolic homeostasis, inflammation and cancer: current evidence and future perspectives. Int J Mol Sci 2016;17:E999.

23 Zhang X, Shin J, Molitor TW, Schook LB, Rutherford MS: Molecular responses of macrophages to porcine reproductive and respiratory syndrome virus infection. Virol 1999; 262:152-162.

24 Chung HK, Lee JH, Kim SH, Chae C: Expression of interferon-alpha and $\mathrm{Mx} 1$ protein in pigs acutely infected with porcine reproductive and respiratory syndrome virus (PRRSV). J Comp Pathol 2004;130:299-305.

25 Choi UY, Kang JS, Hwang YS, Kim YJ: Oligoadenylate synthase-like (OASL) proteins: dual functions and associations with diseases. Exp Mol Med 2015;6:e144.

26 Helbig KJ, Eyre NS, Yip E, Narayana S, Li K, Fiches GN, McCartney EM, Jangra R, Lemon SM, Beard MR: The antiviral protein viperin inhibits hepatitis $\mathrm{C}$ virus replication via interaction with nonstructural protein 5A. Hepatol 2011;54:1506-1517.
27 Seo JY, Yaneva R, Hinson ER, Cresswell P. Human cytomegalovirus directly induces the antiviral protein viperin to enhance infectivity. Sci 2011;332:1093-1097.

28 Nasr N, Maddocks S, Turville SG, Harman AN, Woolger N, Helbig KJ, Wilkinson J, Bye CR, Wright TK, Rambukwelle D, Donaghy H, Beard MR, Cunningham AL: HIV-1 infection of human macrophages directly induces viperin which inhibits viral production. Blood 2012;120:778-788.

29 Teng TS, Foo SS, Simamarta D, Lum FM, Teo TH, Lulla A, Yeo NK, Koh EG, Chow A, Leo YS, Merits A, Chin KC, Ng LF: Viperin restricts chikungunya virus replication and pathology. J Clin Invest 2012;122:4447-4460.

30 Tang YD, Na L, Zhu CH, Shen N, Yang F, Fu XQ, Wang YH, Fu L.H, Wang JY, Lin YZ, Wang XF, Wang X, Zhou JH, Li CY: Equine viperin restricts equine infectious anemia virus replication by inhibiting the production and/or release of viral Gag, Env, and receptor via distortion of the endoplasmic reticulum. J Virol 2014;88:12296-12310.

31 Zhang Y, Burke CW, Ryman KD, Klimstra WB: Identification and characterization of interferon-induced proteins that inhibit alphavirus replication. J Virol 2007;81:1124611255.

32 Fang J, Wang H, Bai J, Zhang Q, Li Y, Liu F, Jiang P: Monkey viperin restricts porcine reproductive and respiratory syndrome virus replication. PLoS One 2016;11:e0156513.

33 Mason CP, Tar AW: Human lectins and their roles in viral infections. Molecules 2015;20: 2229-2271.

34 Huskens D, Schols D: Algal lectins as potential HIV microbicide candidates. Mar Drugs 2012;10:1476-1497.

35 Xu S, Pei R, Guo M, Han Q, La J, Wang Y, Wu C, Zhou Y, Lu M, Chen X: Cytosolic phospholipase $\mathrm{A} 2$ gamma is involved in hepatitis $\mathrm{C}$ virus replication and assembly. J Virol 2012;86: 13025-13037.

Pathological Features Caused by TSHSV 